\title{
Application of IoT for Counterfeit Prevention in Fast Moving Consumer Goods
}

\author{
A.Mohamed Abbas ${ }^{1}$, S. Vimal ${ }^{2}$, U. Maheswaran ${ }^{3}$, T. Porselvi ${ }^{4}$, B. Meenakshi ${ }^{5}$ \\ \{abbasasfaq@gmail.com ${ }^{1}$, vimalshan@gmail.com ${ }^{2}$, er.maheswaran@gmail.com ${ }^{3}$, \\ hod.eee@sairam.edu.in ${ }^{4}$, Meenakshi.eee@sairam.edu.in ${ }^{5}$ \} \\ ${ }^{1}$ Senior Faculty, Computing and Informatics Department, Mazoon College, Muscat, Sultanate of \\ Oman, ${ }^{2}$ Assistant Professor, Department of Information Technology, Jeppiaar Engineering College, \\ Chennai, India, ${ }^{3}$ Assistant Professor, Department of Electronics and Communication Engineering, \\ Rajalakshmi Institute of Technology, Chennai, India, ${ }^{4}$ Professor and Head, Department of Electrical and \\ Electronics Engineering, Sri Sairam Engineering College, Chennai, India, ${ }^{5}$ Professor, Department of \\ Electrical and Electronics Engineering, Sri Sairam Engineering College, Chennai, India,
}

\begin{abstract}
The current research provides research into the techniques used and in making fraudulent identification of fast-moving consumer goods, which can be used to combat the distribution of counterfeit goods in various domains. Different strategies can be used to identify and control the distribution of counterfeit goods at different levels. The list of strategies and methods explored in this report include: asset verification technology, which can be used to distinguish between real and counterfeit goods, tracking and tracking technology, which can be used to control the purchase and distribution of chains to make it easier to find counterfeit goods in the supply chain. and marking ecommerce web analytics technology, which can be used to identify fraudulent product vendors and set up organizations and processes. Each method may not be a valid solution to the problem of production and distribution of counterfeit products. The fraud problem is related to many different domains and assets..
\end{abstract}

Keywords: FMCG, Top Companies, Counterfeit Prevention, Brand Protection, smart labels.

\section{Introduction}

Long haul market stuns, abrupt changes in standards of conduct, and sensational vacillations sought after, have made issues in the store network, particularly shopper products chains (FMCGs). There are contrasts between the organic market for fundamental food sources (e.g., oil, flour, sugar, salt, milk, meat). There are postponements and blunders in conveyance, item shakiness, upset stockpiling conditions, and so on Proficiency, straightforwardness, and soundness of the FMCG store network are addressed.

The truth of the matter is that this is a market where the assistance area overwhelms. Of the complete number of enlisted lawful elements, $35 \%$ to $40 \%$ of enrolled organizations are in the FMCG distribution stage. As a rate, the most noteworthy number of representatives is in the FMCG situation class (about 10\%), with the FMCG deals income share in WB absolute GDP of $11 \%$. What's more, the WB district is fascinating in research since it is a business 
opportunity for in excess of 20 million purchasers, portrayed by critical financial and social contrasts in all areas, making it serious.

Settle, Procter and Gamble, and Coca Cola are among the biggest buyer products organizations on the planet. Settle in Switzerland, for instance, works in excess of 2,000 brands that incorporate everything from nutrients to cold food sources. Critically, inside the quick buyer merchandise area, piece of the overall industry rivalry is high. Accordingly, organizations center more around bundling not exclusively to pull in clients, however to keep up the timeframe of realistic usability and item trustworthiness.

\section{Related Study}

The top Indian FMCG organizations with their subtleties available

Hindustan unilever limited company - Debt to equity - 0, Cratioeffiency -1.31 , yield 1.08, Price - 11.66, sales - 11.87, PE - 74.16, ROE - 86.11, ROCE - 117.25, MCAP 543560.

ITC company- Debt to equity - 0 , Cratioeffiency -4.02 , yield -4.55 , Price -4.77 , sales 5.61, PE - 21.07, ROE - 25.66, ROCE - 31.55, MCAP - 274588.57.

Nestleindiacompany - Debt to equity -0.03 , Cratioeffiency -1.78 , yield -1.22 , Price 55.32, sales - 13.35, PE - 76.14, ROE - 70.27, ROCE - 98.16, MCAP - 158549.38.

Britanniacompany - Debt to equity - 0.28 , Cratioeffiency -1.45 , yield -1.01 , Price 33.6, sales - 7.53, PE - 46.7, ROE - 35.94, ROCE - 41.47, MCAP - 83488.56.

Marico company- Debt to equity - 0.03 , Cratioeffiency -1.71 , yield -2.32 , Price -8.15 , sales - 12.5, PE - 46.88, ROE - 28.95, ROCE - 35.69, MCAP - 51008.02

\section{Methodology}

Current section contains the materials and methods of this research work. The dataset collected from UCI repository and tradebrains. The data set contains laboratory values of companies profile with detailed information. The below information have given about the list of the attributes.

1. Mass Serialization Technologies

2. One dimension-Bar Code

3. QR code

4. Physical Fingerprint Technology

5. Other overt technologies

6. Other covert technologies

7. Radio Frequency Identifier

The Weka 3.8.9 has implemented to get the optimal solution of the above dataset. The below approaches have implemented and got optimal solution. 


\section{Results And Discussion}

Study results indicates the significance of IoT implementation in FMCG for counterfeit prevention based various technologies. Quality analysis of various parameter including Mass Serialization Technologies, One dimension-Bar Code, QR code, Physical Fingerprint Technology, Other overt technologies, Other covert technologies, Radio Frequency Identifier.

Table 1. Number of technologies implementation in different company

\begin{tabular}{|l|l|l|l|l|l|l|}
\hline S.No & Techniques & $\begin{array}{l}\text { Hindustan } \\
\text { unilever } \\
\text { limited }\end{array}$ & ITC & Nestleindia & Britannia & Marico \\
\hline 1. & $\begin{array}{l}\text { Mass } \\
\text { Serialization } \\
\text { Technologies }\end{array}$ & 5 & 5 & 4 & 4 & 4 \\
\hline 2. & $\begin{array}{l}\text { One dimension- } \\
\text { Bar Code }\end{array}$ & 8 & 6 & 7 & 7 & 6 \\
\hline 3. & QR code & 10 & 10 & 9 & 8 & 7 \\
\hline 4. & $\begin{array}{l}\text { Physical } \\
\text { Fingerprint } \\
\text { Technology }\end{array}$ & 6 & 6 & 5 & 7 & 6 \\
\hline 5. & $\begin{array}{l}\text { Other overt } \\
\text { technologies }\end{array}$ & 7 & 7 & 8 & 3 & 5 \\
\hline 6. & $\begin{array}{l}\text { Other covert } \\
\text { technologies }\end{array}$ & 6 & 6 & 5 & 5 & 4 \\
\hline 7. & $\begin{array}{l}\text { Radio } \\
\text { Frequency } \\
\text { Identifier }\end{array}$ & 4 & 2 & 5 & 6 & 6 \\
\hline
\end{tabular}

Figure 1. Number of technologies implementation in different company

Number of technologies implementation in different company

Radio Frequency Identifier

Other covert technologies

Other overt technologies

Physical Fingerprint Technology

QR code

One dimension-Bar Code

Mass Serialization Technologies
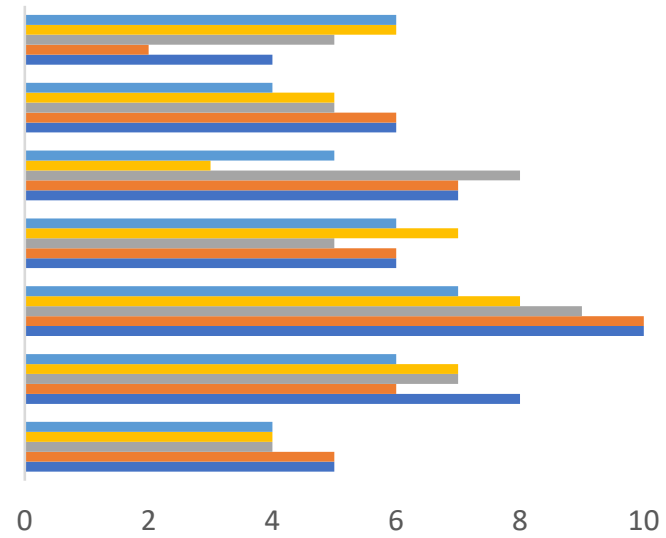

Marico Britannia $\square$ Nestleindia $\quad$ ITC $\quad$ Hindustan unilever limited 
QR code based technologies in implemented in almost all top companies. Still there are technical and logical issue in implementing.

\section{Importance of Counterfeit information}

Counterfeit information should be known be the consumer in general. Information on counterfeit products enable consumer for choosing good products. The statistical analysis of Counterfeit information on products identification on smart tags is 97.74, 2.259 percentage incounterfeit information obtained by consumer is higher than not obtained consumers (Figure 2\& Table 2).

Table 2. Importance of Counterfeit information

\begin{tabular}{|l|l|l|}
\hline & Total & Percentage \\
\hline Obtained & 346 & 97.74 \\
\hline Not obtained & 8 & 2.259 \\
\hline
\end{tabular}

Figure 2. Importance of Counterfeit information

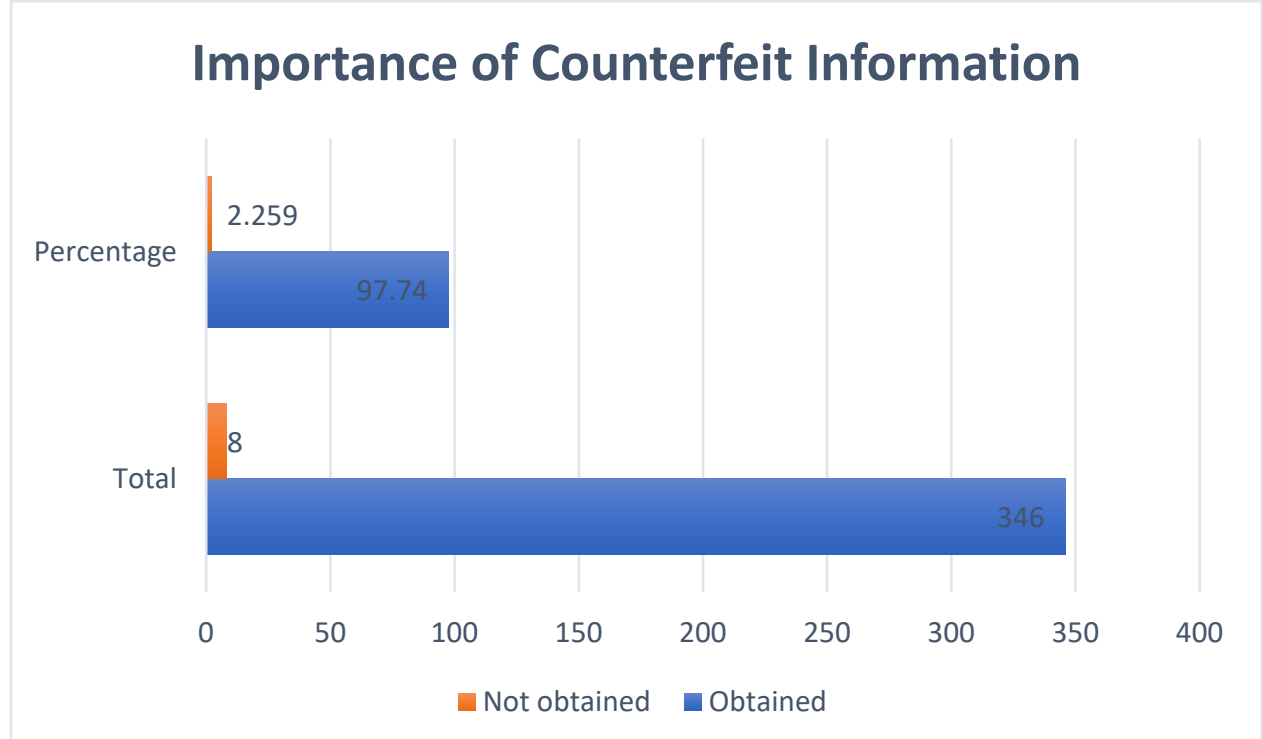

The need to combat counterfeiting in the global manufacturing network is widely recognized and various alternatives and approaches have been proposed to address this issue $[1,2]$. These processes apply to the product business $[2,14]$. There are arrangements based on the IoT based technologies that may be below the lower stage, as IoT based technologies users are less available $[15,16]$. Then again, preparations based on ink are highly adaptable to the point of execution $[11,15]$, but they are easy to imitate [14]. A few experts suggest the use of preparations based on glittering materials [9] or unusual examples [10], but there is a need for more help with these methods. Product tracking and tracking arrangements based on the use of single product bottle numbers using the OCR method can be considered, but the disadvantage 
is that the accuracy of the reading and use of different text styles and numerical programs for different product types [7-11]. Frameworks of object identification and anti-fraud based on the use of QR codes are generally accepted by consumers and often require a camera with a camera [2-6]. The naming of Blockchain similarly finds its use in the production network of application managers $[15,16]$, and its new record recording could allow for the selection of cloud-based frameworks soon.

\section{Conclusion}

This paper outlines the implementation of a pilot project that uses a variety of methods to create a product validation framework and false arguments in the product business. This method is powered by IoT, distributed by archiving and investigating information, mobile applications, and randomly labelled based on unique QR codes. The use of awesome labels creates a parallel space, where everything that happens is visible, using the new techniques provided by Horizon 2020 TagItSmart! project [1-4]. If it is not a very common problem, note that the standard standard tags distinguish the type of object that currently does not provide data for the same item [5-7]. It is worth noting that the GS1 Digital Link Standard has been redesigned in TagItSmart! making and donating marks the use of QR code, (IoT based Smart Tags), closed field communication (NFC), and Bluetooth to transmit information to their customers [8-10]. The common idea is to provide limited web-enabled provision to improve consumer purchasing experience, strengthen product reliability, and improve store network availability and efficiency.

Surprisingly the use of smart labels is that the general protests of the massive market that are not considered part of the IoT biological system can be provided by sharp labels that allow them to radically change their individual status by relying on environmental changes [11-14]. Another important part of this method used to detect human-enabled detection is cell phone access everywhere with their cameras [15].

\section{References}

[1] Wang, L.; Wells, P. Automobilities after SARS-CoV-2: A Socio-Technical Perspective. Sustainability 2020, 12, 5978

[2] Obrenovi'c, B.; Du, J.; Godinic, D.; Tsoy, D.; Shafique Khan, M.A.; Jakhongirov, I. Sustaining Enterprise Operations and Productivity during the COVID-19 Pandemic: Enterprise Effectiveness and Sustainability Model. Sustainability 2020, 12, 5981.

[3] Agbehadji, I.E.; Awuzie, B.O.; Ngowi, A.B.; Millham, R.C. Review of Big Data, Artificial Intelligence and Nature-Inspired Computing Models for Performance Improvement towards Detection of COVID-19 Pandemic Case and Contact Tracing. Int. J. Environ. Res. Public Health 2020, 17, 5330

[4] Hirata, A.; Kodera, S.; Gomez-Tames, J.; Rashed, E.A. Influence of Absolute Humidity and Population Density on COVID-19 Spread and Decay Durations: Multi-prefecture Study in Japan. Int. J. Environ. Res. Public Health 2020, 17, 5354.

[5] Worldometer. Reported Corrona Cases and Deaths by Country, Territory, or Conveyance. Available online: https://www.worldometers.info/coronavirus/ (accessed on 25 July 2020).

[6] Nientied, P.; Shutina, D. Tourism in Transition, the post Covid-19 Aftermath in the Western Balkan. Co-PLAN Resil. Ser. 2020, 2, 1-20. 
[7] Ivanov, D. Viable supply chain model: Integrating agility, resilience and sustainability perspectives-Lessons from and thinking beyond the COVID-19 pandemic. Ann. Oper. Res. $2020,1,1-21$.

[8] Y.G. Kim et al. Consumer acceptance of a quick response (QR) code for the food traceability system: Application of an extended technology acceptance model (TAM). (2016)

[9] L. Li. Technology designed to combat fakes in the global supply chain (2013)

[10] H. ScholtenDefining and analysing traceability systems in food supply chains"chapter in "Advances in food traceability techniques and technologies" (2016)

[11] G. Baldini, I.N. Fovino, R. Satta, A. Tsois, E. Checchi, "Survey of techniques for the fight against counterfeit goods. N.C.K. Yiu. An NFC-Enabled Anticounterfeiting System for Wine Industry. (2014)

[12] A. Chéron. La protection et la contrefaçon de vins en France et à l'étranger" [The protection and counterfeiting of wine in France and abroad] Le Journal du Net (28 June 2013)

[13] B. Lecat. Fraud and counterfeit wines in France: an overview and perspectives. Br. Food J. (2017)

[14] R. Pender. Counterfeit Wine - Its Impact on the Business of Wine. (March 2010)

[15] Harald Sundmaeker "Internet of Food and Farm 2020", Chapter in "Digitising the Industry"(2016).

[16] W. SarniFrom Dirt to Data, The second green revolution and the Internet of Things" Deloitte Rev. (2016) 